\title{
IUELTAL
}

\section{Portraying the English Morphological Development of Indonesian-English Interlanguage Learners}

\author{
Rudi Suherman \\ Universitas Persatuan Islam \\ rudipipit11@gmail.com \\ Lia Maulia Indrayani \\ Universitas Padjadjaran \\ lia.maulia.i@gmail.com/Lia.maulia@unpad.ac.id \\ Ekaning Krisnawati \\ Universitas Padjadjaran \\ ekaning@unpad.ac.id
}

\begin{abstract}
:
The study intends to see the interlanguage morphological structure observed in communicative tasks of ten Indonesian learners of English as a Foreign Language. To achieve this purpose, Qualitative method with quantified data is employed in this study embracing the crosssectional approach. The data are taken from the utterances produced by 10 (ten) L2 learners who performed three different communicative tasks; semi-structure interviews, 5 picture descriptions, 2 spot differences. The researcher found 356 English morphological structures produced by the learners, and 66 of them are analysed as data samples the analysis is started by profiling their morphological acquisition. It helps the researcher to provide a vivid picture of their English morphological development stage. After analysing the data, the result shows that the English morphological structures produced by the L2 learners in this study are divided into three types: Suppliance, non - suppliance and over - suppliance structures. Suppliance structure refers to structure that is received by grammatical rules in standard English. Meanwhile, the other two types of structure refer to idiosyncratic structures as an innate characteristic of interlanguage morphology. Besides, English morphological development
\end{abstract}


stage is compatible with the Processability Theory (PT). The learners who have acquired higher morphological structure also have already acquired lower morphological structure.

Keywords: English morphological development, interlanguage learners, processability theory.

\section{Introduction}

First language ( $\left.\mathrm{L}_{1}\right)$ is generally acquired by children in natural way. They acquire it at ease. The process of language acquisition seems does not take so much effort. It is due to the existence of a device called Language Acquisition Device (henceforth LAD). It is a device that is naturally installed inside children's mind. It exists inside the children's minds until they enter adulthood. It enables children to acquire language easily due to the brain plasticity and helps them to have native-like competence (Damayanti, 2008; Hamilton, 2014). Therefore, they are mostly able to have good conduct of their $L 1 / L 2$ without learning it consciously.

L2 acquisition process is usually taken place at the later stage when the learners have already acquired their $L 1$. It normally takes place in the adulthood phase. It does not seem like $L 1$ acquisition, $L 2$ acquisition process for adult learners is normally through conscious of learning, series of long practice and extensive repetition in which is sometimes quite tiring. It is due to the brain starts to lateralize that makes it lost its plasticity. It causes LAD no longer to exist from adult learner's mind. As an exchange, they start utilizing Latent Psychological Structure (henceforth LPS) when learning L2 (Riyanto, 2012; Saville-Troike, 2012).

LPS emerges when maturation takes place. As an exchange of LAD, LPS helps learners to attain the $L 2$ that is being learned. In producing utterances, adult learners employ Interlingua identification - a strategy used to identify the resemble features of Native Language (NL) and Target Language (TL) its function is to help them in identifying the similarity features between two languages.

It is argued that the utterances produced by the learners when trying to communicate meaning in TL become the high preference data to be examined in interlanguage topic (Tarone, 2018). This type of data freshly comes out of learners' minds and it also reflects the psycholinguistic processed occurred, this situation is called attempted meaningful performance.

A major issue in second language acquisition research and language teaching is the topic of how students obtain a subsequent language (De Bot et al., 2007; Doughty \& Long, 2008). This process of $L 2$ acquisition is generally believed to take place through developmental sequences. When the process is being acquired, the L2 learners produce sentences or speech that has its own features and uniqueness. It is due to the system of TL that is being learned is not thoroughly acquired. The interplays between established $L 1$ and $L 2$ emerge new form of language, this form is well known as interlanguage. It is stated that term interlanguage refers to the linguistic system evidenced when an adult second language learner endeavor to utter meanings in the language being studied (Kimppa et al., 2019; Tarone, 2018) 
The interlanguage is viewed as an independent system that is different from learners' first language and the system of language that is being studied or targeted language but linked to both language systems as a result of learners 'perception toward the interference of the language inside their mind.

It is argued that interlanguage can majority be investigated on adults who were learning second language. It is considered as characteristics of adult second language learner, passing the puberty and thus cannot be expected to be able to employ LAD. Adult language learners will utilize LPS in mind. This structure will activate when learners have acquired meaning of the TL from their first language. Thus, the utterance produces will not be as identical as the utterance produced by the native speaker of TL.

There are five characteristics of interlanguage, one of them is overgeneralization of the TL. The learner display of having acquired a general rule, but does not yet comprehend all the exception to that rule For instance, the learner may use the past tense marked - ed for all verb, regular and irregular alike: talked, booked, studied, *swimmed, * eated, *runned. The overgeneralization shows vivid proof of learning development, in that it shows that learner has acquired a TL rule, but it also shows what the learner has yet to master. To the extent that L2 learners create overgeneralization, one may contend that they are utilizing a similar procedure as that utilized by L1 learners.

Today, it is widely known that any second language learning follows certain theoretically established and empirical supported developmental sequence. One of the established theories on this issue is known as Processability Theory (henceforth PT) (Bettoni, 2009; Pienemann, 2012; Riyanto, 2012). This theory can generally analyze present statuses of student's second language improvement. Thinking about the way of second language improvement gives significant knowledge into what students are prepared to get in the outside/second language at a given point in time. This can bolster second language learning both in regular and instructional settings.

PT develops certain hierarchy procedures of language development that one can handle. It is started from word as the simplest procedure and gradually moves to phrasal, sentence, until subordinate clause procedure as the most complex procedure that one can handle. Pienemann (2013: 14) states that the fundamental assumption underlying this theory is that learners acquire grammatical inventory following the procedure for two reasons: (1) because the hierarchy is implicational ordered, i.e. every stage is a necessary prerequisite for the next one and (2) because the procedure reflects the time-allotted in language generation.

According to PT, the learner must choose between limited options other than to create this chain of importance. Expressions can't be amassed without words being appointed to classes, for example, 'thing' and 'action word', and sentences can't be gathered without the expressions they contain, etc. The way that students must choose between limited options in the way they take in the improvement of preparing methods follows from the time course of language age and the structure of handling techniques. This is how they design of language age compels language advancement.

In the context of language learning in Indonesian, one of the most fascinating interlanguage cases is between English - Indonesian. Comparing to other global languages English is 
considered as the language that is most widely studied by Indonesian learner (Marcellino, 2006; Ningsih, 2016). English has also become a compulsory subject at secondary level, and it also becomes one of high-stake exam subjects given to secondary school students which is known as national exam (Emilia \& Hamied, 2015). However, it is not widely spoken by the community.

It is therefore interesting to see the forms of English - Indonesian Interlanguage produced by Indonesian learners who are categorized as EFL/L2 Learners. The utterances which will be produced by them may differ to those produced by English native speaker nor be exact translation from Indonesia. The produced utterances will become interlanguage repertoire and consider as learners' creativity who are gradually improving their language competence in the process of learning L2. This study intends to investigate the interlanguage morphological structure observed in communicative tasks of ten Indonesian learners of English as a Second Language (henceforth L2 learners). It also aims to see their morphological development based on PT. Their English morphological acquisition must be determined first. It helps the researcher to provide a vivid picture of their English morphological development stage.

Many researchers have studied interlanguage syntax and other linguistics elements embracing PT, such as Sakai (2008), and Riyanto (2012), yet as far as the writer's concern, only a few of them who primarily concern on morphological aspect(Bettoni et al., 2010). Therefore, in this research, the writer will focus on the aspect of morphological development of L2 learner who is majoring in English education program in Universitas Persatuan Islam, Bandung. Particularly the stage of English morphological structure they occupy viewed from morphological development in PT.

\section{Literature Review}

\subsection{Processability Theory}

The logic underlying PT according to Pienemann (2005) at any phase of advancement the student can create and understand just those etymological structure which the present status of the language processor can deal with. It is consequently urgent to comprehend the design of the language processor and how it handles a subsequent language. This empowers one to foresee the course of improvement of L2 phonetic structures in language creation and appreciation across dialects.

PT is applicable for both English morphology and syntax. This study will only focus on English morphology based on PT literature. The morphology development stages are structure implicationally. In the L2 student at phrasal system stage is anticipated to have just obtained the lower morphological procedures; phrasal procedure and lemma access (Bettoni et al., 2010; Riyanto, 2012).

This study also incorporates the interlanguage theory (Tarone, 2018) to have more comprehensive and profound result. Interlanguage theory has become one of the central theories in the field of language acquisition. This theory states that a language learner tends to have independent language systems that differs from their Native Language $(N L)$ and Target Language (TL) being learned, but linked to both NL and TL by interlingual identification in the perception of the learners (Widyastuti, 2015). 


\subsection{English Morphological Structure Based on PT}

The following table summarizes the developmental stages for English Morphological structure based on PT utilizing feature unification.

Table 1. Developmental Stage of English Morphological Structure Based on PT (Pienemann 2005:24)

\begin{tabular}{|c|c|c|c|c|}
\hline & Procedure & $\begin{array}{l}\text { Morphological } \\
\text { outcome/stage }\end{array}$ & Structure & Example \\
\hline 4 & Sentential & $\begin{array}{l}\text { Interphrasal } \\
\text { morphology }\end{array}$ & $\begin{array}{l}3^{\text {rd }} \quad \text { person } \\
\text { singular }-s\end{array}$ & Rudi likes animals \\
\hline \multirow[t]{2}{*}{3} & Phrasal & Vp morphology & $\begin{array}{l}\text { Aux }+v: \\
\text { Aux be }+v-i n g\end{array}$ & $\begin{array}{l}\text { I am going, she is } \\
\text { sleeping }\end{array}$ \\
\hline & & Np morphology & $\begin{array}{l}\text { Phrasal plural }-s \\
\text { (marker) }\end{array}$ & $\begin{array}{l}\text { Those boys } \\
\text { Few books } \\
\text { Seven white dogs }\end{array}$ \\
\hline 2 & Category & Lexical morphology & $\begin{array}{l}\text { Past - ed } \\
\text { Plural -s } \\
\text { Verb-ing }\end{array}$ & $\begin{array}{l}\text { Putra arrived } \\
\text { Apples } \\
\text { Working }\end{array}$ \\
\hline 1 & $\begin{array}{l}\text { Lemma } \\
\text { access }\end{array}$ & Invariant forms & $\begin{array}{l}\text { Single } \\
\text { constituent }\end{array}$ & Dog, book, computer \\
\hline
\end{tabular}

It is stated that PT provide a fundamental distinctive feature between lexical, and sentential morphology. It is based on the procedure involved in each of these types, the level of processing procedures decides the sequence in which these types of affixation process emerge. The procedures include both syntax and morphology. Since this study focus on morphological aspect, the detail of each procedures involving linguistic aspect for morphological outcome of each stage is explained as follows

\section{Single Constituent}

Single constituent formula is the first stage of morphology acquisition. In this stage, a learner has not created handling systems yet. Along these lines, conceivable, morphological results at this stage are invariant types of things and action words, with no morphological variety for example; book, table, cat, go, sleep, drink.

Some types of morphemes are considered to be lexicon due to the notion that no complex mechanism is required to proceed with them. For example, a tense marking morpheme such as "ate" is considered as a lexical morpheme because there is no need for information exchange between words or phrases (Bettoni, 2009; Pienemann, 2005; Sakai, 2008). Therefore, this stage is assumed to be the easiest one to be acquired by EFL/ESL learners regardless of their ages. 


\section{Verb -ing as Lexical Verb}

There are four separate morphological structures which are predicted to appear, two characterizing nominal items (plural - $\mathrm{s}$, and possessive's) and two verbal items ( $\mathrm{V}$ - ing, and past - ed) each structure values with its nature and function, and likely to be applied by the learner in ways which may be different from how a native speaker uses it.

\section{Lexical plural -s}

Lexical plural - s belongs to category procedure characterizing nominal item. No trade of linguistic data is required for this procedure, since the diacritic component is to be set apart in one constituent as it were. At the end of the day, this sort of morphology can be created by lexical activities. Along these lines, it is designated "lexical" in PT. lexical morphemes plural - s without quantifiers (e.g., windows, floors) are predicted to develop at this stage.

\section{Past - ed}

Past - ed belongs to category procedure characterizing verbal item. There is no trade of syntactic data is required for this procedure, since the diacritic component is to be set apart in one constituent as it were. At the end of the day, this sort of morphology can be delivered by lexical activities. In this way, it is designated "lexical" in PT. lexical morpheme past - ed (e.g., studied, jumped) is to develop at this stage.

Past- ed still belongs to category procedure. It is considered to be highest stage in category procedure. It hypotheses to emerge after lexical plural $-\mathrm{s}$. Past - ed marker give more grounded instance of a delicate obstruction. It was fairly late contrasted with unpredictable past structures, for example, came and went. In this stage, learner must be able to assign a past tense morpheme to a verb. It is also known as regular past verb.

\section{Phrasal Plural -s}

At stage 3 , in which phrasal procedure creates, the data trade between two constituents inside the expression becomes possible. In request to trade data between two constituents, diacritic highlights are to be set apart in a few constituents and their worth data must be coordinated between constituents. The guessed morphology result at this stage is called phrasal morphology. The case of thing phrasal morphology, specifically phrasal plural $-s$ with a quantifier.

\section{Aux be + V - ing}

PT additionally estimates that action word phrasal morphology, that is, the understanding between the AUX and the action word structures develops after thing phrasal morphology is set up. AUX requires the accompanying action word to have a specific structure (Yamaguchi, 2010). That is, modals (e.g., can, may) must be trailed by the base types of the action words, while other AUX, for example, be and have, require morphological stamping on action words. To be increasingly explicit, dynamic be is required to happen with $V$-ing, perfective have with $\mathrm{V}$-ed, and detached be with $\mathrm{V}$-ed. Note that latent development is clarified dependent on the Lexical Mapping Hypothesis in PT.

\section{Third Person Singular - s}

The activation the next stage, the Sentential, allows for long-distance, sentential agreement between SUBJ and the lexical V. The learner can assemble all the phrases to the 
$\mathrm{S}$ - node and assign the function to NP's grammatical function according to the sentential information. The morphological outcome generated by this type of "feature unification "in third person singular $-\mathrm{s}$ of present tense $(3 \mathrm{sg}-\mathrm{s})$.

\subsection{Acquisition Criteria}

In this study, the first three productive use needs to be shown with lexical variation can claim that a particular morpheme or structure is acquired. In addition to this, the emergence criterion is used to see the emergence production of each obligatory context observed by counting at least four tokens (Pallotti \& Peloso, 2008; Widyastuti, 2015)

\section{Research Methodology}

\subsection{Participants}

The data of this study were taken from the utterances produced by 10 (ten) L2 learners. There are ten (10) college students majoring in English Education as the participant of this study. They are currently studying at one of local teacher training colleges located in Bandung, namely STKIP Persatuan Islam with the age range of $19-21$. They are from firstyear students who are currently taking their second semester. They are chosen purposively based on their speaking subject score in previous semester. They individually perform three different communicative tasks; semi-structured interview, picture description, spot differences (Adams, 2015; Gill et al., 2008). In addition, the learners are treated equally. They are given the same tasks which must be accomplished under limited time. Each of them is accompanied by an interviewer who has been told in term of how the process of data elicitation is carried on.

Semi - structured interview is selected due to its effectiveness in gaining intended data in compared to free conversation (Adams, 2015; Alwasilah, 2011) The questions in the interview are adopted from IELTS speaking test which consist of three part; introduction, long turn, and discussion. Each learner is asked to talk about various things to elicit morphological structures. For example, they are asked about their holiday to trigger past ed, or are asked to tell a daily activity that usually do by their family member to trigger 3 rd person singular $-\mathrm{s}$.

The learners are given 4 different pictures and are asked to describe what those pictures are about. The pictures are provided as media to help students composing a writing. In this study, the writer uses the picture as the instrument to gain the data. This picture book has been employed extensively in cross -linguistics experiment (Bettoni, 2009; Yamaguchi, 2010) and it is very common for language development/acquisition study to adopt pictures to elicit data.

This task contains various linguistics context, particularly in English morphological aspect such as phrasal procedure stages particularly progressive Aux be $+\mathrm{V}-\mathrm{Ing}$, and past - ed when they make up stories based on the cartoon strips. Besides that, after describing he given pictures, the learners are also asked about their opinion in regard to the situation within the picture. This idea aims to trigger $\mathrm{S}$ - procedure or interphase morphology.

The learners have to play "Spot the difference" with the interviewer. In this game, they are provided a set of two photographs that are almost identical but had minor differences. They have to take turns to question and answer in order to find out the distinctive features 
between the provided photographs. This game has been broadly used to elicit spoken data in SLA research. This task can support the previous task in eliciting a range morphological construction which appear in PT.

\subsection{Data collecting procedures}

Describe Data collecting is one of essential step in conducting a research. In this study, the data is taken from three different communicative tasks; the semi-structure interview picture description, and spot difference. The data are collected through series of step as follows:

1. Each learner performs three different communication tasks; semi-structure interview, picture description tasks, and spot difference tasks.

2. Each learner' production speech is recorded using audio digital recorder while they are performing those tasks.

3. The result of transcription is considered as the data.

4. The data are then selected based on the need of answering the research questions.

5. The data are classified and interpreted based on PT an interlanguage theory.

\subsection{Data Analysis Procedures}

In this paper, the writer relies on the data transcription of speech produced by the participant. Those data are taken at one point in time, and will be analyzed using the grand and supporting theories that have been mentioned previously. Method of data analyzing performed in this research are as follows;

1. The collected data are described and analyzed qualitatively based on the PT to investigate whether or not the learners have acquired the target structure.

2. The collected data are further analyzed by seeing the number of occurrences of the structures. It aims to validate the minimum number of acquisition criteria/emergence criterion.

3. Over - suppliance and non - suppliance structures are also analyzed to see what motivate the learner to produce them.

4. Each learner's acquisition profile is further analyzed using implicational scale of English see their acquisition stage.

5. The conclusion is drawn from the result of above, and suggestion is made for further research.

\section{Findings}

\subsection{English Morphological Development of the Learners}

This section presents the results of the analysis of English Morphological development utilizing implicational scaling. The data are elicited from three different communication tasks. On the table 4, each column is represented by three different marks. The first mark "+" is given for the structures which reach standard minimum of the acquisition criteria. In the other word, the structure is generally have mastered by the participant. The second mark "-" indicates that there is negative evidence, or the structure is not fully mastered, 
while the mark "I" given when there are no linguistic contexts for the structure or the structure does not appear.

Table 2. The Implicational Scale of English Morphological Development

\begin{tabular}{|c|c|c|c|c|c|c|c|c|c|c|c|}
\hline \multicolumn{2}{|c|}{ Morphological stages and their structures } & \multicolumn{10}{|c|}{ The L2 Learners } \\
\hline $\begin{array}{c}\text { Morphological } \\
\text { Stage }\end{array}$ & Structure & 1 & 2 & 3 & 4 & 5 & 6 & 7 & 8 & 9 & 10 \\
\hline Interphrasal & $\begin{array}{c}3^{\text {rd }} \text { person singular }- \\
s\end{array}$ & - & + & - & - & I & - & - & + & + & - \\
\hline Verb phrasal & Aux be $+\mathrm{V}$-ing & - & + & - & - & l & + & + & + & + & + \\
\hline Noun phrasal & Phrasal plural -s & + & + & - & - & l & + & + & + & + & + \\
\hline \multirow{3}{*}{ Lexical } & Past-ed & + & + & - & + & 1 & + & 1 & 1 & 1 & 1 \\
\hline & Lexical plural -s & + & 1 & + & + & - & 1 & + & + & + & + \\
\hline & Lexical V-ing & + & + & + & + & + & + & + & + & + & + \\
\hline Invariant form & Single constituent & I & + & I & + & + & I & + & 1 & I & 1 \\
\hline
\end{tabular}

As shown in the table above, the learners' morphological development appeared to have for the most part follow the formative levels as anticipated by the theory. All learners who participated in this study has surpassed single constituent structure stage. They were able to formulate and retrieve lemma from their mental lexicon to the context given. They were also able to produce higher stage, lexical Verb - ing, characterizing nominal item. They were able to start assigning lemmas with their characteristic diacritic in the context given, Aux be + ing, and 3 rd person singular $-\mathrm{s}$.

The learner no.1 did not produce single constituent structure. However, he was able to produce and acquired lexical $\mathrm{V}$ - ing which was higher stage than single constituent. It can be said that he had surpassed the single constituent structure. In addition, he also acquired lexical plural $-s$ structure and past $-s$ structure. These two structures belong to lexical morphology which is predicted to be acquired after lexical $V-$ ing. Beside lexical morphology, he also had acquired NP Morphology which was higher than the lexical morphology. However, he had not yet fully developed two other morphology structures, Aux be $+\mathrm{V}$-ing, and 3 rd person singular $-\mathrm{s}$. it can be concluded that his morphological development was up to NP morphology as it was represented by phrasal plural -s structure.

The learner no.2 acquired the two lowest morphological structures of morphology; single constituent and Lexical V - ing. She skipped the lexical plural -s as it is shown y sign "I", yet able to produce three other higher morphological structures; past -ed, phrasal plural -s, and Aux be $+\mathrm{V}$-ing. It can happen as the communicative tasks given were not able to trigger her to produce lexical plural $-s$ structure. Therefore, there was no linguistics evidence or there was no context for it. Although the slashes "I" mark was found on the learner no.2, her morphological development was compatible with PT. In addition to this, her morphological development had reached VP morphology as it was represented by Aux be + $\mathrm{V}$-ing structure. She was one stage higher than the learner no.1 and was able to acquire the highest morphological structures, 3rd person singular $-s$, based on PT.

The learner no.3, was like the learner no.2. He did not produce single constituent structure. However, he was able to produce and acquired lexical $V$ - ing which was higher stage than 
single constituent. It can be said that he had surpassed the single constituent structure. He also produced the other four higher morphological structures based on PT. However, he only produced a few of those structures which was less than required numbers. His morphological development had reached lexical morphology as it was represented by lexical plural structure in second stage.

The learner no.4 acquired four different morphological structures. She produced and acquired single constituent, Lexical $\mathrm{V}$ - ing, Lexical plural $-\mathrm{s}$, and past - ed structure respectively. She also produced the other three higher morphological structures based on PT. However, he only produced a few of those structures which was less than required numbers. There was no contradictory evidence found. In addition, her morphological development had reached lexical morphology as it was represented by past -ed structure in second stage. She had reached higher morphological development than the learner no.2.

The learner no.5 was only able to proceed and acquire lexical V - ing structure of the morphological development. She was not able to proceed to the higher stage. She probably had acquired quite a bit of knowledge about upper morphological structures yet less exposure and practice. The knowledge may be acquired through aural and visual observation of other learners. Therefore, she probably should get more time to engage and practice with those structures which helped her to get the practical knowledge of the higher morphological structures.

The learner no. 6 did not produce single constituent. However, she was able to produce and acquired lexical $\mathrm{V}$ - ing which was higher stage than single constituent. It can be said that he had surpassed the single constituent stage. She also did not produce lexical plural-s it shown by "I" mark. However, she produced and acquired three other morphological structures that had higher stage than lexical plural-s. Those three morphological structures are past -ed, be $+\mathrm{V}-$ ing, and phrasal plural. She also produced 3 rd person singular which was categorized as highest morphological structure based on PT. however, she had not acquired this structure yet. As the minimum number of the structures was below acquisition criteria.

The learner no.7 acquired the first three stages of morphological structures. Those structures are single constituent, Lexical $\mathrm{V}$ - ing, Lexical plural -s, structure respectively. He did not produce past - ed structure but he was able to produce and acquire two other morphological structures; phrasal plural $-\mathrm{s}$ structure and Aux be $+\mathrm{V}-$ ing structure. Even though the slash "/ "mark was found, the finding did not contradict morphological development which was predicted by PT. In addition, his morphological development had reached VP morphology stage as it was represented by lexical plural -s structure.

The learner no.8 did not produce single constituent structure. However, he was able to produce and acquired lexical $V$ - ing and lexical plural -s structure which was higher stages than single constituent. It can be said that he had surpassed the single constituent structure. In addition. These two structures belong to lexical morphology which was predicted to be acquired after lexical $\mathrm{V}$ - ing. he did not produce past -ed structures at it was shown by slash"I" mark. Even though the slash "/ "mark was found, the finding did not contradict morphological development which was predicted by PT. it was because he also acquired plural phrasal $-s$ and 3 rd person singular $-s$ structure. It can be concluded that his 
morphological development was up Interphrasal morphology. He was one of the learners who were able to proceed and acquired the highest morphological structure.

The learner no.9 seemed to have the same morphological development as leaner no.8. She did not produce single constituent and past - ed structure as it was shown by the slash "I" mark. The absentees of these two structures were probably caused by the ineligibility of the communicative task to trigger her to produce the structure. However, she acquired the other five morphological structures. In short, her morphological development was compatible with PT.

The learner no.10 seemed to have similar morphological development as leaner no. 8 and no.9. She did not produce single constituent and past - ed structure as it was shown by the slash "I" mark. The absentees of these two structures were probably caused by the ineligibility of the communicative task to trigger her to produce the structure. However, she only acquired the other four morphological structures and had not yet acquired the highest morphological structure. Her morphological development is on stage lower than two former learners. Overall, her morphological development was compatible with PT.

\section{Discussion}

The English morphological structures produced by the L2 learners in this study are divided into three types: Suppliance, non - suppliance and over - suppliance structures. These three types of structure are commonly found in EFL learners who are struggling to acquire the morphological patterns in English (Riyanto, 2012). The suppliance structure refers to structure that is received by grammatical rules in Standard English.

The non suppliance structure refers to the Morphological structures that is not in line with grammatical rules. It is due to the absence of rule of Morphological structures. Rules that they have not yet learned. However, this type of data is considered as an attempt to capture emerging interlanguage data.

The over suppliance refers to the Morphological structures that is in line with grammatical rules. However, the structure contains extra information which is not needed. They tend to generalize the rule they have learned. It is one of the major characteristics of interlanguage learners (L2 Learners) whose skill is categorized as transition competence. Among the five characteristics of interlanguage, overgeneralization of English rule become the most dominant factors of interlanguage variation that found in this study.

The L2 learners are able to comprehend the general rules of TL. However, they neglect or do not know the specific or idiosyncratic rules owned by the language. They simply generalize the rules to all related language cases they encounter. In this study, the L2 learners mark present verb for third person subject by adding -s, like sleeps, takes, even for wented (rather than goes), or watchs (rather than watches) or mark -s on uncountable non like peoples This psycholinguistic process become the evidence that learners have mastered certain rules in target language, and it also shows what learners have not yet learnt or mastered. (Widyastuti, 2015)

In every developmental stage, the L2 learners of this study can produce utterances which are in line with the obligatory context as the requirement of the acquisition criteria such as when they talked in past time context. Generally, they can produce past - ed for the regular form, phrasal plural $-\mathrm{s}$ on noun and some of them are even able to produce verb $-\mathrm{s}$ in the 
context agreement between subject and verb. They can formulate the expressions to the $S$ - hub and allot the capacity to NP's linguistic capacity as indicated by the sentential data. The morphological result created by this kind of "include unification "in third individual solitary - s of current state.

Interphrasal morphology stage as it is represented by 3 rd singular $-\mathrm{s}$ seemed to be the most difficult structure to be acquired. There were only three learners, (no.2), (no.8), and (no.9), who had developed up to this stage. They had attained this structure and able to unify the subject - verb agreement in singular context. The sixth other learners can produce this category. However, they have not yet developed fully function of sentential procedure as they only produce only one or two structures. It was still below the minimum number of acquisition criteria. Most of them produced non- and over- suppliance 3rd singular - $s$ structures. It represents the learners' current state of morphological development. In other words, their language knowledge related to this procedure was not fully established. Therefore, an extensive and deliberate practice is probably required to lead them to gradual automatized of knowledge (Kimppa et al., 2019)

In addition, the implicational scale that is presented on the finding shows that the morphological development path of EFL by the Indonesian learners who participate in this study is mostly in line with the current developmental PT. These morphological development stages are order implicationally There is no negative evidence (marked '_'above) for any structure in the hierarchy in the presence of positive evidence (marked ' + ') for any higher-level structure. In other words, the L2 learners at NP morphology stage have already acquired the lexical morphology and invariant form.

To sum up, the current research has contributed to enrich the literature work in the discussion of English morphological development of EFL learners-based on PT. The finding has important implications for at least two essential respects. Firstly, the EFL teachers have to take into consideration the English morphological structures that need to be taught to the EFL learners. It should be started from invariant from and gradually to the higher procedure level of morphological structures. Secondly, the EFL learners need to get more exposure to the morphological structures that have been taught. It aims to make the them able to use the structure accurately and more spontaneously.

\section{Conclusion}

It can be concluded that the L2 learner who participates in this study mostly have acquired English morphology according to the proposed theory. Their English morphology development is also found to be generally in line with the stages in PT. The learners who have acquired higher level English morphology structure with higher level of processing also have acquired lower level of English morphology structure. Their level of morphological acquisition is in line with development and their level of the study the higher-level learners can proceed. Although the data of this study are taken from a few Indonesian EFL learners, it still gives fruitfully contribute to shedding light on the developmental path of EFL and to the progression of PT by recognizing increasingly itemized formative stages for English morphology. It is accepted that this investigation prompts future exploration for the further improvement of the field of SLA just as ESL/EFL education. 


\section{References}

Adams, W. C. (2015). Conducting Semi-Structured Interviews. Handbook of Practical Program Evaluation: Fourth Edition, August 2015, 492-505. https://doi.org/10.1002/9781119171386.ch19

Alwasilah, A. haedar. (2011). Pokoknya Kualitatif : Dasar-Dasar Merancang dan Melakukan Penelitian Kualitatif. Pustaka Jaya.

Bettoni, C. (2009). Processability Approaches To Second Language Development and Second Language Learning. Studies in Second Language Acquisition, 31(3), 502-503. https://doi.org/10.1017/s0272263109090391

Bettoni, C., Riyanto, S., Lee, Kim, Emilia, E., Dao, L. H. T., Bettoni, C., Biase, B. Di, Mukai, Y., Di Biase, B., Kawaguchi, S., Yamaguchi, Y., \& Iwasaki, J. (2010). PDF Record. ProQuest Dissertations and Theses, 14(6), 882-886. https://doi.org/10.1017/s0272263109090391

Damayanti, I. L. (2008). Is the Younger the Better? Teaching English to Young Learners in the Indonesian Context. 1(1), 31-38.

De Bot, K., Lowie, W., \& Verspoor, M. (2007). A dynamic systems theory approach to second language acquisition. Bilingualism. https://doi.org/10.1017/S1366728906002732

Doughty, C. J., \& Long, M. H. (2008). The Handbook of Second Language Acquisition. In The Handbook of Second Language Acquisition. https://doi.org/10.1002/9780470756492

Emilia, E., \& Hamied, F. A. (2015). Systemic Functional Linguistic Genre Pedagogy (Sfl Gp) in a Tertiary Efl Writing Context in Indonesia. TEFLIN Journal - A Publication on the $\begin{array}{llll}\text { Teaching and Learning of English, } & 155 .\end{array}$ https://doi.org/10.15639/teflinjournal.v26i2/155-182

Gill, P., Stewart, K., Treasure, E., \& Chadwick, B. (2008). Methods of data collection in qualitative research: Interviews and focus groups. British Dental Journal, 204(6), 291295. https://doi.org/10.1038/bdj.2008.192

Hamilton, R. (2014). Bedtime Stories In English : Field-Testing. 10(3), 249-254.

Kimppa, L., Shtyrov, Y., Hut, S. C. A., Hedlund, L., Leminen, M., \& Leminen, A. (2019). Acquisition of L2 morphology by adult language learners. Cortex, 116, 74-90. https://doi.org/10.1016/j.cortex.2019.01.012

Marcellino, M. (2006). English Language Teaching in Indonesia: A Continuous Challenge in Education and Cultural Diversity. TEFLIN Journal, 17(1), 57-69. https://doi.org/10.15639/teflinjournal.v19i1/57-69

Ningsih, H. K. (2016). Multilingual re-instantiation : Genre pedagogy in Indonesian classrooms (PhD Thesis). February. http://www.isfla.org/Systemics/Print/Theses/HKartikaNingsih_thesis.pdf

Pallotti, G., \& Peloso, A. (2008). Acquisition Sequences and Definition of Linguistic Categories !2008-03-31 !2008-10-08 !2008-12-03 ! The Open Applied Linguistics Journal, 1(1), 77-89. https://doi.org/10.2174/1874913500801010077

Pienemann, M. at al. (2005). Cross-Linguistic Aspects of Processability Theory (M. Pienemann (ed.)). John Benjamins Publishing company. https://doi.org/https://doi.org/10.1075/sibil.30

Pienemann, M. (2012). Processability Theory and Teachability. The Encyclopedia of Applied Linguistics, 1-6. https://doi.org/10.1002/9781405198431.wbealog58

Riyanto, S. (2012). Dutch-Indonesian interlanguage Psycholinguistic study on syntax. Wacana, Journal of the Humanities of Indonesia, 14(1), 154. 
https://doi.org/10.17510/wjhi.v14i1.54

Sakai, H. (2008). An analysis of Japanese university students' oral performance in English using processability theory. System, 36(4), 534-549. https://doi.org/10.1016/j.system.2008.03.002

Saville-Troike, M. (2012). Introducing Second Language Acquisition. In Introducing Second Language Acquisition. https://doi.org/10.1017/cbo9780511808838.002

Tarone, E. (2018). Interlanguage. The Encyclopedia of Applied Linguistics, II, 1-7. https://doi.org/10.1002/9781405198431.wbealo561.pub2

Widyastuti, I. (2015). A Processability Theory Study: Past -ed Acquisition in University Learners in Indonesia. 2(1), 78-84. https://doi.org/10.26555/adjes.v2i1.2024

Yamaguchi, Y. (2010). The Acquisition of English as a Second Language by a Japanese Primary School Child: A Longitudinal Study from a Processability Viewpoint (p. 266). 